\title{
Mutual Transparency or Mundane \\ Article Transgressions? Institutional Creeping on Facebook
}

\section{Daniel Trottier}

University of Alberta, Canada. dtrottie@,ualberta.ca

\begin{abstract}
This article explores the post-secondary sector's adoption of social media. Social media plays an increasing role in the visibility of personal information. The term refers to a set of web-based services that facilitate the authorship and distribution of media between users. The most popular social media site is Facebook with over 750 million users worldwide. Facebook was originally launched as a service for university students to author and distribute information about their personal identity, interpersonal connections, and social activities. While Facebook has since expanded its scope beyond universities, student life remains a heavily 'Facebooked' phenomenon. University administrators are keenly aware of their students' presence on this site, and are adopting new practices to harness Facebook as an extension of their professional duties.

This paper draws upon findings from a series of fourteen semi-structured face-to-face interviews with various administrators and employees at a medium-sized university in Eastern Ontario. As Facebook first emerged in an academic context, these findings provide a rich example of how institutions can scrutinize populations using social media. These findings suggest that institutional surveillance on Facebook stems from ground-up practices prior to implementing top-down mandates, suggesting that these practices have developed from institutional users' personal experiences with the site. As well, the visibility of the university and its reputation is offered by respondents as motive for scrutiny, suggesting a discourse of mutual transparency of both the university as an institution as well as its student population.
\end{abstract}

\section{Introduction}

Social media are web-based services that facilitate information exchange between users, with Facebook being the most popular social media site with over 750 million users worldwide (FB Statistics 2011). Facebook began as a social networking service for undergraduate students at select universities in the United States, allowing these students to author and distribute information about their personal identity, interpersonal connections, and social activities. Today, a broader demographic from different social spheres has converged on the medium.

Facebook claims that it is used 'to give people the power to share' (FB About 2011), suggesting comfort and control for users. Yet like so many electronic media, Facebook is a 'leaky container' (Lyon 2001) and both seeping and stronger outflows are common occurrences. By virtue of using Facebook, students make themselves visible to a large population of individuals, primarily friends and colleagues. And while there has been considerable analysis of the type of peer-to-peer visibility afforded by Facebook, institutions also access this site. Here, institutions refer to formal organizations that provide services to or otherwise manage a specific population.

Trottier, Daniel. 2011. Mutual Transparency or Mundane Transgressions? Institutional Creeping on Facebook. Surveillance \& Society 9(1/2): 17-30.

http://www.surveillance-and-society.org | ISSN: 1477-7487

(C) The author, 2011 | Licensed to the Surveillance Studies Network under a Creative Commons

Attribution Non-Commercial No Derivatives license. 
A cursory search of news media suggests that social media impacts nearly all aspects of social life (Roper 2010; Sweney 2010a; Sweney 2010b; Dodd 2010). Facebook and other social media are increasingly interlaced with a host of institutional functions. This institutional prevalence is a by-product of the site's popularity among users. As a rapidly growing user base volunteers information about themselves, their peers, and their social world, corporate bodies have become particularly eager to capitalize on this valuable commodity, with designers and businesses attempting to exploit this informational goldmine.

This paper explores how institutions, focusing particularly on universities, are adopting social media. While Facebook has expanded its scope beyond universities, student life remains a heavily 'Facebooked' phenomenon. Facebook contains a wealth of content that various organizational units within a university are keen to explore and exploit. Their presence on sites like Facebook entail distinct types of surveillance that focus on a set of individuals, increasing the institutional visibility of personal information. This institutional presence on Facebook marks the latest attempt by schools and universities (Monahan and Torres 2010), to watch over and control their populations. Students that make themselves visible to one another on social media unintentionally augment institutional surveillance. This relates to what danah boyd (2007) identifies as invisible audiences in social networking, such that users do not know who can access their personal information.

This paper helps clarify Facebook's status for institutions. The fact that the site offers unprecedented access to personal information suggests that it is a valuable institutional resource. Yet it can also be a liability to universities and other institutions in that it augments their own visibility in ways that are difficult to manage. Users openly criticize schools, workplaces, and corporations, and these criticisms are retained and easily accessible through the site's search function as well as through external search engines like Google. Institutions and individuals may be mutually transparent, as both are made visible through social media. Yet institutions develop practices to manage risks on social media, while exploiting the visibility of individual users.

After outlining some theoretical and methodological considerations, this paper is organized into sections that chronologically depict how universities have adopted social media. It begins with the emergence of institutional use from interpersonal experience. It then addresses the perceived appropriateness of using Facebook on behalf of the university, and the prescription of a complaints-driven approach to social media. The visibility of the university on social media, with its reputation in student hands, triggers a task force to determine official guidelines. Social media like Facebook are also used to publicize security incidents. Finally, respondents contemplate their future involvement with social media.

At the time of writing no guidelines exist at a university level to shape employee conduct, with protocols and best practices still in negotiation. Hence, part of the appeal of this analysis is precisely the fact that norms and protocols for such institutional monitoring are currently emerging. Surveillance Studies benefits from considering how surveillance-related institutional policies develop, with user-initiated, bottom-up practices informing official mandates. This paper points to instances where institutional scrutiny assume a more categorical approach, namely in targeting student parties that risk tarnishing the school's reputation. Facebook's recently enhanced search feature makes it easier for the university to target what they consider to be relevant content.

\section{Theorizing social media and the domestication of surveillance}

Social media have an increasing impact on relations between institutions and individuals, and the nature of that impact requires abstraction. For all the discussion of social networking sites and social media, there is no consensus regarding what social means. We may unpack this term using a Weberian understanding of social action. Social media's growth lies in their ability to foster communication, as they facilitate a 
networked sociality made up of exchanges between social actors, institutions, and social contexts. Andreas Wittel (2001) has commented on the theoretical implications of such a networked sociality. His work is less concerned with these networks as it is with underlying social dynamics. In particular, networking as a contemporary practice in the Western world marks a fusion of labour and leisure. The information sector relies on 'barcamps', happy hours, and other non-work work practices where leisurely sociality becomes a means to enhance capital. Everyday life is further colonized by work, notably through the cultivation, commodification and exploitation of social ties. Wittel's work predates social media, but he identifies the boundaries between social realms--work and play, public and private-as compromised by the promotion of corporate networking. Such theoretical grounding underscores that social media can be distinguished from other online technologies through their emphasis on pre-existing, offline social ties (Trottier and Lyon 2011).

The notion that private lives are increasingly exploited and scrutinized is also anticipated by material on the domestication of technology. Roger Silverstone (Silverstone and Haddon 1996) first wrote about television's presence in the domestic realm, noting that audiences play an active role in adding meaningand value - through consumption. Focusing on domestication underscores the importance of the situated context in media studies. This focus produces a more robust social science, enriching academic, but also corporate understandings of information and communication technologies. Silverstone's treatment of users' communicative efforts anticipates the emergence of social media, and its emphasis on user-to-user communication to generate value. Silverstone also focused on tensions that arose when new technologies enter the domestic sphere. The mediation of everyday life underscores tensions between the familiar and the strange (ibid.), and forces a reconsideration of the private sphere. Again, this anticipates concerns over privacy violations (boyd 2008) and compromised identities (Turkle 2011) with social media. And while the domestic sphere often refers to the homestead, Silverstone was careful to point out that the domestic is in fact a broader concept. Everyday domestic life, once the overlooked remainder of capitalist production, is made visible through new media (Poster 2004). Recent scholarship using Silverstone's approach has turned to mobile technology, and how its domestication leads to contested boundaries between public and private life (Ling 2004). Ward (2005) furthers this approach in her research on what she calls the second generation internet, and its emphasis on flexible, user-driven content.

Both academics and industries have a growing interest in the domestication of technology. That is, user activity is increasingly under scrutiny. Users are treated as a source of innovation, but also a potential liability. Watching over them is entirely in line with state and institution-led attempts to control populations (Scott 1998). Indeed, information technologies have long been central to institutional surveillance (Dandeker 1990). But what is unique with social media and universities is that an institution is utilizing a domestic technology. The domestication of technology is a growing concern for Surveillance Studies. Lyon (2001) rightly observes that the rapid uptake of mobile devices marks a progressive creeping of surveillance into everyday life by enabling users to be located and tracked in a pervasive manner. Despite the expansion of new forms of surveillance and visibility in a wireless world, the effects of this visibility are far from obvious. Webcams (Koskela 2006) and social media (Albrectslund 2008) enable an empowered visibility, such that their users control how they present themselves. Yet the voluntary use of these technologies augment surveillance enclosures where the totality of everyday life is visible to businesses and governments (Andrejevic 2007). Both perspectives hold empirical purchase. But the domestication of surveillance has grown too vast, and so this research will focus on the university sector.

Institutional surveillance on Facebook fits in a broader history of keeping order in schools. Control and discipline have been attempted through a variety of architectural, pedagogical and technological approaches. In the United Kingdom, a national database tracks student activity (Lyon 2010). Other technical solutions for managing and monitoring students include $\mathrm{x}$-rays at entrances and drug testing for athletes. At universities smart cards are pervasive, tracking and regulating the movement of students on 
campuses. These technologies exert control over students by focusing on their physical presence. Social media complicate this focus by offering a new terrain for disorder to occur.

Social media first emerged as services for individuals - students in this case-before being adopted as tools for institutions. Beer and Burrows (2007) offer an early account of the consequences of social media in the university. The initial effect is the heightened visibility of faculty and teaching staff online in a searchable and editable format. This is experienced as an upset to staff and faculty under scrutiny, yet the full consequences of social media in the academy remain to be seen. Students are increasingly making themselves visible; all while other watchers are taking an increased interest in sites like Facebook. When Beer and Burrows published their article, Facebook was only recently established beyond the Ivy League network. While their study uncovers how universities are subject to exposure, these institutions are responding by turning to social media themselves. Universities are still scrutinized by students using social media, but they are increasingly able to manage their own visibility as well as to take advantage of the visibility of students. Social media further compromise the boundaries between everyday sociality and institutional scrutiny. Not only are universities able to manage their reputation online, but doing so affords them scrutiny and control of student population, by virtue of that population's increasingly public presence. They capitalize on the augmented visibility of students on cross-contextual platforms, which in turn augments the surveillance and control of that population.

\section{Methodology}

The findings below draw on a series of fourteen semi-structured, face-to-face interviews with employees at a mid-sized university in Eastern Ontario, Canada. These employees were interviewed between February and June 2009. Participants were reached by way of key insiders at the university, including two vice-presidents. Snowball sampling was also used to locate additional respondents. The decision to pursue qualitative data is justified by the need to develop an in-depth understanding of these emerging practices. Of the fourteen participants, two respondents worked for campus security, two for marketing and communications, four were employed by residence life, two were tenure-track professors, two were human rights advisors, and two worked for the registrar's office. The university in question maintains strong relations with alumni and other donors. However, recent incidents have raised concerns about its reputation as a 'party school', which the administration is struggling to manage. This coincides with a rapid uptake of social media like Facebook by undergraduates. The university is currently coming to terms with how to manage its own involvement on this site.

Interviews with participants addressed four themes. The first theme considered relevant policies at the time of Facebook's emergence. This clarified how the university first framed social media as well as the gaps and challenges posed by this approach. The second theme considered practices, notably how social media are used in a professional setting. As social media are not conventional institutional services, it is appropriate to focus on how employees first approached them and in what capacity they were used as part of their work. The third theme examined the perceived validity of information found on social media as well as the perceived appropriateness of obtaining information in this manner. Again, because Facebook was rooted in interpersonal exchanges, respondents negotiated their position among themselves but also with students. The fourth theme considered experiences using social media, both in a personal and professional setting. The novelty of this subject means that respondents raised additional issues. As much as possible respondents were able to address these issues during the interviews.

\section{Genesis of Facebook as a professional tool}

Given Facebook's interpersonal origins, its emergence as an institutional service warrants exploration. Here, Facebook emerged organically. Instead of a mandate from above, respondents reported a groundlevel realization among employees that relevant information could be retrieved on the site. Many key 
operators were already Facebook users, or worked with someone who used the service. In the majority of cases personal accounts were used to access information. One exception is the case of a human rights advisor who previously abstained from Facebook and created an account strictly for professional duties. In addition to harnessing a pre-existing familiarity with the site, these employees blurred the line between professional and personal presence by using the latter to augment the former.

As there were no guidelines for using Facebook, professional practices first emerged to facilitate minor tasks. Respondents used Facebook to identify students by putting a face to a name. A member of campus security reports:

Facebook in the past has allowed us to confirm identities of people. It has allowed us to - and when I say confirm identities, I really do mean simply in an anecdotal way, more along the lines of confirming for the people in the office that we're talk about the same person, not so much as institutionally identifying someone. (Sec_2)

The respondent describes an innocuous entry for the professionalization of Facebook by noting its quasiofficial use to confirm an identity during a conversation. Using Facebook in a professional setting does not mark a rupture from personal usage. Rather, it resembles personal usage extensively, as employees rely on personal accounts as well as navigation skills gained from personal experience. While it was used to identify persons of interest, the consequences and appropriateness of that identification are not obvious to respondents, and for that reason employees used Facebook casually.

These findings present a diagram of institutional surveillance that fuses user-initiated, practices into a larger structure. Institutions take advantage of information that individuals - students in this case - submit online. In this case they do not initiate, but rather exploit the heightened scrutiny afforded by social media. Moreover, the university's ability to watch over students on Facebook is facilitated by employees' familiarity with the site in an interpersonal context. Many of these employees were Facebook users first, and this experience is leveraged to monitor students on behalf of the university. The employees who usher social media like Facebook into the institution are a hybrid category. They operate on behalf of the academic institution, acting as its eyes and ears. Yet this is only possible through their presence on Facebook as individual users. This personal-professional hybrid facilitates the institutional adoption of an otherwise domestic technology. Not only can employees access Facebook content with their personal accounts, but their experience as users also allows them to navigate the site. This is a key feature of the augmentation of institutional surveillance by the interpersonal use of social media. The skills gained by users watching over users directly translate to the university being better suited to scrutinize their students.

At the time of the interviews nobody had the specific task of managing social media on behalf of the university. Instead, employees already working for the university were put in charge of social media because of their knowledge and enthusiasm for these services. Respondents were generally passionate about this topic. A coordinator from marketing and communications states:

I sort of do this in addition to my regular job because I have a love for it. And so, a lot of the time, most of the stuff that I do is outside of work hours because I'm on these places anyways and I like researching them, it's just a passion of mine. (Mktg_2)

The decision to put enthusiasts in charge of social media is sound, although it also has important labour implications. Because of their passion for social media, these employees assume added responsibility with no financial compensation. This echoes what authors like Clay Shirky (2008) have said about decentralized organizing: that corporations benefit from input provided by individuals who use social media for intrinsic rewards. From a labour studies perspective new media augment what is already expected of workers (Dyer-Witherford 1999). 
The majority of interviewees report that social media have greatly complicated their duties. This counters the perception that social media facilitate the management of student populations. Indeed, the sheer volume of information now accessible is staggering. A marketing and communication employee states:

It's almost impossible to find out what everybody is doing at [the university]. (...) It's very explosive, this use of social media that it's pretty hard to keep on top of, there's no one person that can control or audit everything that's happening. (Mktg_1)

Not only does Facebook grant access to a vast body of personal information, but the absence of explicit guidelines from the site and from the university greatly complicate what can be done with this information. A residence employee reports that instead of witnessing events as they unfold, incidents discovered through Facebook occur at an undisclosed point in time. Likewise, a security officer reports on its mainstream status, noting that Facebook is a burden because of the vast access to information that it offers:

It's so widely used and has become such an accepted staple in people's daily routines that if there is harassment that is going to take place, there is a good chance that it will find its way onto Facebook as well. (...) It's more of a bone of contention for most people in our service and I mean that along, broadly speaking. Generally speaking, we will all tell you that it has created more work for us than it has ever solved. (Sec_2)

Facebook augments the visibility of university life, such that employees struggle to make use of all that is made visible. This suggests a kind of institutional growing pain in regards to Facebook. While it is currently treated as a burden, this is because the institution has not yet developed proper strategies to cope with social media.

\section{Perceived appropriateness of monitoring Facebook}

Facebook offers universities unprecedented access to student information with no guidelines for appropriate usage. This has led to uncertainty among university officials. Facebook is recognized as a source of relevant information, and is accessed by universities for this reason. But employees and students are ambivalent about whether or not this information should be used for institutional purposes. Respondents report that content found on the site has been uploaded in an interpersonal context, and that they felt uncertain about using it for other reasons. This uncertainty is also exemplified in situations where the university might intervene in student conversations online. An admissions coordinator offers that she does not 'feel comfortable in us jumping in. I don't think it's our place, they don't think it's our place' (Reg_1). Employees and students oppose the university having a visible presence on Facebook. A residence employee conducted a survey to screen student attitudes, finding that they were overwhelmingly opposed to the university's presence on the site. In particular actively seeking out information on Facebook was deemed to be inappropriate. Not only did the survey confirm the admissions coordinator's suggestion that the university should not visibly intervene on Facebook, but also that they should not patrol the site for objectionable content.

Most respondents were quick to point out that they did not actively scour the site. They provided both ethical and logistical reasons to explain this approach. From an ethical standpoint they did not consider actively monitoring the site to be appropriate, which is compounded on top of their uncertainty about acting on Facebook content. However, logistical reasons carried more weight. Respondents claim that navigating the site to find information was incredibly time consuming, especially when users perpetually cope with a changing interface. A communications officer states: 'on a really basic level, now that I'm thinking about morals and ethics, we just don't have the manpower at the time' (Reg_1). Other security 
and residence employees echo this claim, citing time and workload as reasons not to patrol Facebook for relevant content. Despite these constraints, many of the respondents felt entirely justified having a professional presence on Facebook. This was partly based on the accessibility of Facebook's content. One security coordinator privileged logistical reasons over ethical ones, citing the semi-public nature of information on Facebook as justification to act:

I definitely don't have enough hours in the day to spend surfing. And ethics... I don't know so much that it's really ever been questioned if we do visit a Facebook site, I don't think we have ever found ourselves in a position where someone says that it's unethical for you to visit that website. (...) If my ten year old can see it at home, then I don't see any problem with me pulling it up on my computer at work. (Sec_2)

Student reactions indicate a clash between a contextual approach to privacy (Nissenbaum 2009) and one based on mere access. Employees acknowledge that contextual boundaries are a concern, but also that personal information will likely transcend these boundaries. While students may want others to disregard information found on Facebook, one residence coordinator asserts that students themselves disregard the ease with which this information is accessible and the extent to which it is made public:

I think it's funny when people feel like it's private, but again I feel like it's only when it's convenient for them they'll call that and they'll say 'that's private, don't comment on that', or 'that's none of your business', or 'don't use that against me'. Well, this is the image, this is the story you are telling about yourself without you being there to explain yourself. (Res_3)

Another residence employee claims that students are complicit in their own visibility, citing that students are uploading content that is made accessible through its association with Facebook's university networks:

If you're part of the [university] network, you basically have access to pictures of anyone. It's like a database that people have helped create. I can find pictures of anyone on campus, anyone who goes to [the university]. So of course, that's useful. If that's a tool that's available to help keep the community safe, we'll exploit it. (Res_1)

As well, employees describe the inability to ignore information found on the site, and framed this as being hard-wired into all users. A security officer describes the impossibility of not reacting to information found on Facebook, noting that humans are 'creatures of judgement' (Sec_2). The ease with which personal information is found on Facebook, especially when it is the only information available to investigators, strengthens this reactive judgement.

The issues raised by these employees highlight the effects of an increasingly visible social life. Facebook makes personal information accessible, but accessing and acting on this information is controversial. The act of deliberately looking over individuals is especially problematic for employees. Debates over what is public and what is private on Facebook--as well as the meanings held by these terms - spread from interpersonal concerns to relations between institutions and individuals. These tensions are an effect of the domestication of technology, as familiar information exchange is reconfigured in strange ways (Silverstone and Haddon 1996). Despite this uncertainty it is clear that Facebook is a new location for institutional problems. Conversely, it is also a tool to identify and manage these issues.

\section{Complaint-driven activity versus patrolling Facebook}

Campus security, human rights, and residence employees were quick to point out that they took a complaints-driven approach to Facebook. That is, if an incident were brought to their attention from a 
complainant, they would investigate the site. But they claimed that they would not actively search Facebook, and certainly would not wander aimlessly for suspicious content. An investigative approach was frequently cited as a counterpoint to the complaints-driven approach, and was criticized for the ethical as well as practical reasons listed above:

We're not looking at is as an investigative tool. You've probably noticed the whole time we've been talking, that's the first time that I've ever used the term investigative. We don't investigate, we follow up. (Sec_1)

This decision is informed by protocols pre-dating Facebook, as another security employee reports an avoidance of a 'quasi-investigative role at the best of times' (Sec_2). Following up, instead of investigating, suggests a reactive rather than proactive approach. Given the vast amount of information that could warrant investigation employees prioritize material that others brought to them. A residence employee echoes this sentiment:

If there's a complaint or something and then it comes up in the information that we've gathered that there's actually pictures on, or it's a harassment issue and someone comes to us and says it's happening on Facebook then part of the information gathering will then be going to Facebook to see if that is. But it's reactive, it's not a proactive 'go and scour Facebook for information' ever. (Res_2)

By focusing on outside complaints, these employees rely on non-employees--typically students and local residents - to direct them to persons and incidents of interest. This approach facilitates their duties because external agents are informally enlisted to scrutinize the site. Their own ability to monitor student activity is augmented by their connection to the greater community. A residence employee claims that they 'don't ever go seek out things on Facebook but if it's bought to my attention we don't ignore it' (Res_3). The university's ability to watch over its student population is augmented by relying on other users to watch over each other online. Not only is this an effective labour-saving strategy, but it also enables a more penetrating gaze. Having friends watch over friends on Facebook enables the university to side-step privacy settings employed by users. Institutions thus capitalize on domestic technologies and the interpersonal visibility that these technologies generate.

Despite endorsing a reactive, complaints-driven approach, respondents conceded that they proactively search and scrutinize Facebook in particular situations. Leading up to events like the annual homecoming celebration, they search and monitor Facebook events and groups:

When homecoming, the debate happened, yes, there were people in my office who sort of went in and sort of printed or took an inventory of the kinds of things that were being said. (Mktg_2)

A coordinator from admissions states that senior members of the university's administration have employed this proactive scrutiny:

It was the Dean of Student Affairs monitoring Facebook and let the police know about all these keggers that were going on. (...) And the police contacted these people beforehand and said, 'nope, not happening. Good luck'. (Reg_1)

Employees generally describe their Facebook monitoring in terms of responding to complaints about specific individuals. Yet categorical suspicion emerges based on homecoming events and a student party culture. This suspicion emerged in the interest of the school's reputation, a point that is further explored below. Proactive searching on Facebook accompanies this suspicion. This is a contradiction of employees' 
own best practices. Despite claims that patrolling is not an adopted practice, it is logistically sound when searching for information about student parties. The ethical implications remain to be sorted out. This development marks a shift from the surveillance of individuals to something distinctly categorical. In other words, Facebook is now used to watch over abstract problems, not just student biographies. Yet the focus on categories still implicates students and their personal information.

The balance between reactive and proactive approaches to social media warrant further exploration, especially as different branches of academic and other institutions connect with sites like Facebook. Likewise, Facebook's changing features and privacy settings suggest that new conditions of visibility will arise. The site's search function has recently augmented its scope (Wable 2009), which affects the kinds of information that can be quickly accessed as well as what is made visible to non-users.

\section{University reputation and mutual transparency}

Although the principal focus of this study was students' heightened visibility in the wake of social media, administration and staff were also concerned with the way their university was made visible through social media. The marketing and communications department is especially concerned with virtually everybody shaping the university's reputation in a public forum. These concerns amplify longstanding practices where potential students learn about the school from upper-year students. Often these students post harmful or inaccurate descriptions of the university on Facebook. This is especially concerning when high-school students and their parents are weighing their options for post-secondary education. In other instances students hosting a party or making inflammatory comments reflect poorly on the university when they publically confirm its reputation as a party school, or one that struggles with racial insensitivity. Employees in the registrar's office confirm that students on Facebook publicize the school's reputation. This is used as a justification for an institutional effort to monitor the site. A marketing coordinator likens Facebook to a kind of feedback mechanism that the university should harness, stating that ' $[u] n l e s s$ you sort of gauge what's going on, you can't just adjust what's going on in your real presence' (Mktg_2). A wealth of consultants and public speakers stress the importance of managing an institution's reputation online. The marketing and communications department is no stranger to these services:

There are a whole new bunch of businesses that are now saying, 'for a fee, we will tell you what is going on in all these different social media platforms'. There's one called [business name] and I've got a free account. And so you can put in search terms (...) and they'll churn this report and they'll search blogs, social networking sites, for what is being said. (Mktg_2)

A communications officer was struck by a consultant's recommendation that 'you basically have to go there because you're already there' (Mktg_1). These services rest on the claim that universities are already present and visible on social media regardless of their actual involvement. This supports Beer and Burrows' (2007) work on social media surveillance. The multi-contextual nature of social media conversations coupled with a growing user population means that the university is subject to unprecedented exposure.

In light of these concerns, the marketing and communications department monitor university-themed groups for discussion. Respondents claimed that they do not conspire to monitor individuals, but simply seek out false information. While they felt tempted to intervene on these spaces, they did not think that this would be well received by students. Posting a response in a student-led discussion would make their presence visible, and be subject to pushback by student users. Instead, they rely on the university's own website to provide accurate information. Yet this was regarded as futile since students do not always rely on official sites for information. They may attempt to create their own Facebook group, but these would 
remain nearly indistinguishable from other content on Facebook. This issue raises a key dilemma that became central to subsequent policy recommendations: should universities establish an institutional presence on these sites, converse with students in student-led spaces, or covertly watch over students? These different strategies reflect differing degrees of visibility of the university, which is seen by marketing and communications as a liability due to student perceptions that the university should not have a presence on Facebook.

This dilemma also gets at the heart of privacy issues on Facebook. Students are clearly comfortable sharing information with one another in a public forum. Yet they regard university administrators' presence as a violation of privacy. This reaction supports a contextual view of privacy (Nissenbaum 2009), as the content they share is meant for their peers, and not a broader audience. Moreover, this is a barrier that employees are only encountering now that their involvement on the site is directly linked to their service to the school.

\section{Emergence of a social media task force}

In response to the above concerns the university created a task force that attempted to make sense of social media's function in the academic sector. Led by the department of marketing and communications, the task force drafted a report for staff, faculty and students who use social media on behalf of the university. This report featured guidelines that resemble the early stages of an official policy vis-à-vis social media. This task force emerged in a climate where little knowledge or consensus exists concerning appropriate conduct for universities on Facebook. Respondents note that existing guidelines were drafted prior to social media and are insufficient to cope with emerging risks. As stated above, social media strategies have long been left to employee discretion and have led to conflicting approaches.

While institutional monitoring on Facebook began with individual employees' practices, the fact that it remained up to their discretion troubles respondents. Discretionary measures, coupled with the growth of social media within and beyond the academic sector, led to growing pressure for the university to provide some kind of policy response. A residence employee suggests the university is reaching a tipping point:

It's become more pervasive. It must change. The university cannot ignore its bearing on university life now. From the type of groups people can have, all that stuff. It's only a matter of time before some kind of policy comes out, or something to do with online usage. (Res_1)

Employees in other departments agreed with this statement, and stated that they were waiting to operate within proposed guidelines. The task force's report included a description of social media for academic purposes, a description of social media usage in general and at the university, as well as guidelines for using social media within the university. Regarding student-led discussions, the report recommends that employees '[m]onitor, but not attempt to control what's being said in social media' and also to 'not become involved in the dialogues in student-administered groups' (Social Media Report 2009). This recommendation reflects an admissions coordinator's usage, who states that they are 'monitoring Facebook' and that they 'never jump in' (Reg_1).

Social media can potentially foster conditions of mutual transparency. Facebook allows any user to view as well as speak on behalf of any other user, brand, or institution. Yet the task force's report recommends the scrutiny of the university's reputation on social media, as well as not adding to this visibility through any further engagement on social media. The university's strategy restores an asymmetrical relation of visibility between students and institutions by watching over sites like Facebook without acknowledging its presence. The task force enables institutional control of a target population by authoring protocols to manage domestic technology. 
The task force struggles to obtain a full understanding of the university's social media presence. Different branches of the university use sites like Facebook for varying purposes, and many do so independently of the administration. The fact that new services emerge while older ones adopt new features complicates attempts to speak authoritatively about social media. The task force accounts for these challenges:

The guidelines had to be such that you couldn't get that specific, and we're talking about something so big and something that's still not totally understood that we wanted to make it enough for people when they phone and say, 'I want to set up a blog, what can you tell me', we'll give them these guidelines. (Mktg_1)

The university wants to pre-empt emerging technologies and practices by drafting an open-ended set of guidelines. This suggests that policy follows technology, and relations with students follow suit. Social media extend new possibilities for the university to watch over students, and related policies are intentionally vague to include these possibilities. Given that these services emerge from interpersonal usage, anticipating innovations is a complex task. A respondent from admissions echoes this approach:

That's one of the challenges we discussed, is that it's got to be, even though it's a policy, it's got to be open ended enough to deal with the challenge of a media that's ever-changing. (Reg_1)

\section{Other functions: Emergency communications}

Although Facebook and other social media were first received by the university as a vast source of information about students and university issues, some departments have contemplated other purposes. Campus security considered using Facebook and microblogging service Twitter to communicate to students and staff:

The one thing that we're taking a look at in our job currently with Facebook is using it in the future as platform for disseminating information. (...) I feel that the social networking sites are an excellent opportunity to disseminate information but we have to ensure that information that's getting disseminated through a third party is trusted, is going to be used appropriately, because the type of platform that we would be looking at is how we disseminate personal safety tips, personal safety information, possibly even campus security alerts during a critical incident. (Sec_1)

While these services would be used to advance knowledge about safety, the respondent presents another important surveillance implication. By broadcasting real-time security alerts campus security is able to exponentially augment their scope when it comes to tracking suspects. Social media's coupling with mobile technology means that students and staff receive notifications about ongoing incidents and can observe and report on behalf of campus security. Here social media amplify pre-existing social networks. In particular, word of mouth dissemination of information is seen as a quick and effective way to communicate security-based issues. Campus security presents enrolling the community as antithetical to an Orwellian vision of surveillance:

I always find it very interesting that when people talk about Facebook and then the next word is security, automatically they have the George Orwell kind of 1984, Big Brother's watching. In our department, it's the exact opposite, right? We're all about sharing information. Our philosophy here is security is everybody's responsibility. Our philosophy here is giving you all the information that you need to make informed decisions about your own safety. So the first thing that when we look at Facebook is 
getting that information to our community. So letting them know what's occurring on their campus and how to react. (Sec_1)

Campus security claims that sharing information provides a useful service to the university. Yet student and staff return the favour when they receive, disseminate, and submit information about ongoing incidents on campus. Students not only make themselves visible in a way that augments institutional surveillance, but also directly contribute to this watching on behalf of the university. Social media offer multiple avenues for individuals to augment institutional scrutiny.

\section{Looking to the future: Uncertainty and commitment}

The initiatives described above suggest that universities are paying more attention to social media. When asked about their future involvement, a residence employee suggested that hate speech is an obvious and appropriate entry point for regulating student content on Facebook:

I guess something I would want the administration to take into consideration when they're making a new policy of whatever, if they choose to, is the fact that you can join any kind of group on Facebook. It can be racist. It can be anything. That's something the university should take into consideration. That if they were to try and attempt to control people's usage, like regular students' usage, that's probably where they would have to start. (Res_1)

The above suggestion furthers the use of social media for categorical suspicion. Monitoring hate speech on campus is an uncontroversial justification for this scrutiny. In that this is an issue that already concerns the university, it stands to reason that they will search for this content.

In general, respondents were reluctant to speculate about what Facebook would look like in the immediate future, nor were they willing to consider how their engagement with social media would evolve. Despite this uncertainty, everyone was confident that they would have an ongoing presence on the site:

I think it's going to continue to grow. I can't really say (...) who can predict that unless you're in there? Yeah, I really can't predict. I really don't know, but I do know we're going to continue to be part of it, whatever it is. (...) And we can't not use social media, we have to be there, we have to be involved, because that's where our target audience is. (Mktg_1)

Their certainty about being involved with Facebook is based on its predominance. As social spheres migrate to social media, the amount of information generated on these sites will continue to be of interest to the university. A residence employee claims that 'everything is happening' on Facebook, from students signing leases to selling furniture, and that it was only a 'matter of time before the university sees the need to have some sort of control' (Res_1) over relevant content. In anticipation of student protest against this development, a communications employee claims that they fail to understand Facebook's privacy affordances:

You'd think that they would know these things but it's ... I think they're under this perception that Facebook is hidden from the internet. Like, for some reason, it's their own little community and no adults are going to come in here, they're not going to look at this. (Mktg_2)

Facebook's continued growth means that the information it hosts is increasingly accessible to the university, and this will impact students' values and expectations. It was more private before, but only 
because fewer people had access to it. As universities assume greater control over information found on Facebook, respondents suggest that students will need to scale back their expectations of privacy.

\section{Discussion}

This paper considers Facebook as a tool for institution-led surveillance. Social media in general and Facebook in particular have gained an unprecedented user base. These users, many of whom are students or employees in the academic sector, generate an ever-growing body of information that has become accessible and easily searchable. Universities and other institutions are using the information located on Facebook in their administrative duties. These practices began with employees bridging pre-existing knowledge about Facebook with institutional tasks, yet their involvement with sites like Facebook become more formal with time.

Social media's use by universities is a recent emergence, but even at this stage key features are observable. Facebook's origin as an interpersonal technology is a unique development for Surveillance Studies. Individual users were initially more familiar with social media, and thus able to use it to the detriment of the academy (Beer and Burrows 2007). Yet individual users employed by post-secondary institutions also enable institutional surveillance through social media. This suggests that universities and other institutions harness interpersonal relations in order to further the institutional control of target populations. In particular, they are using the site to identify relevant categories, such as student parties and hate speech.

The university's adoption of Facebook provides insight about social media surveillance. Individual scrutiny and sociality amplify the kinds of watching that institutions can perform. The people doing this watching often have dual citizenship on Facebook: they started as individual users, and their knowledge of interpersonal surveillance helped them watch over students on behalf of the university. Students also actively contribute to institutional surveillance when they submit complaints involving Facebook and when they respond to security bulletins. Facebook allows institutions to take advantage of individual usage to watch over those individuals. Institutional surveillance on Facebook combines interpersonal features of everyday scrutiny with emerging categories that are easily searched. Institutional control is facilitated through the continued growth of domestic information exchange.

Social media is a domestic technology that has spread to institutions and other realms. Privacy and visibility on Facebook are transforming, and this is the principal tension facing users. Content on Facebook that was previously treated as confidential is now subject to greater exposure. Employees believe that students can no longer consider the site to be private. Insofar as its reputation is implicated in student activity, the university sees Facebook as part of its jurisdiction. Yet recommendations to avoid detection on the site mitigate student opposition. With new features added on a monthly basis, Facebook is an ever-shifting mediascape. Increased scrutiny as well as privacy concerns means that relations between individuals and institutions are also shifting. It stands to reason that these developments occur in other institutions, including workplaces, law enforcement agencies and government branches. Subsequent research should focus on this growth and its consequences for institutional and other kinds of surveillance.

\section{References}

Albrechtslund, Anders. 2008. Online social networking as participatory surveillance. First Monday 13(3). http://firstmonday.org/htbin/cgiwrap/bin/ojs/index.php/fm/article/view/2142/1949/ [Accessed 06/06/2010]. Andrejevic, Mark. 2007. iSpy: Surveillance and Power in the Interactive Era. Lawrence: University Press of Kansas. Beer, David and Roger Burrows. 2007. Sociology and, of and in Web 2.0: Some initial considerations. Sociological Research Online 12(5). http://www.socresonline.org.uk/12/5/17.html [Accessed 06/06/2010].

boyd, danah. 2007. Why Youth (Heart) Social Network Sites: The Role of Networked Publics In Teenage Social Life. In MacArthur Foundation Series on Digital Learning - Youth, Identity, and Digital Media, ed. David Buckingham, 119142. Cambridge: MIT Press. 
boyd, danah. 2008. Facebook's Privacy Trainwreck: Exposure, Invasion, and Social Convergence. Convergence: The International Journal of Research into New Media Technologies 14(1): 13-20.

Dandeker, Christopher. 1990. Surveillance, Power and Modernity: Bureaucracy and Discipline from 1700 to the Present Day. Cambridge: Polity.

Dodd, Vikram. 2009. Facebook murderer jailed for 22 years. The Guardian, March 9. http://www.guardian.co.uk/uk/2010/mar/09/facebook-murderer-jailed-paul-bristol [Accessed 30/03/2010].

Dyer-Witherford, Nick. 1999. Cyber-Marx: Cycles and Circuits of Struggle in High-Technology Capitalism. Urbana and Chicago: University of Illinois Press.

FB About. 2011. About Facebook. http://www.facebook.com/facebook?sk=info [Accessed 20/04/2011].

FB Statistics. 2011. Statistics. http://www.facebook.com/press/info.php?statistics [Accessed 28/07/2011].

Koskela, Hille. 2006. 'The other side of surveillance:' Webcams, power and agency. In Theorizing Surveillance: The Panopticon and Beyond, ed. David Lyon, 163-181. Collumpton: Willan Publishing.

Ling, Richard. 2004. The Mobile Connection: The Cell Phone's Impact on Society. San Francisco: Morgan Kaufmann Publishers.

Lyon, David. 2001. Surveillance Society: Monitoring Everyday Life. Buckingham: Open University Press.

Lyon, David. 2010. Liquid Surveillance: The contribution of Zygmunt Bauman to Surveillance Studies. International Political Sociology 4 (4): 325-338.

Monahan, Torin and Rodolfo Torres. 2010. Schools Under Surveillance: Cultures of Control in Public Education. Piscataway, NJ: Rutgers University Press.

Nissenbaum, Helen. 2009. Privacy in Context: Technology, Policy, and the Integrity of Social Life. Palo Alto: Stanford University Press.

Poster, Mark. 2004. Consumption and digital commodities in the everyday. Cultural Studies 18(2): 409-423.

Roper, Maxine Frances. 2010. The bosses who snoop on Facebook. The Guardian, March 24. http://www.guardian.co.uk/commentisfree/2010/mar/24/bosses-snoop-facebook-twitter-blogs [Accessed 30/03/2010].

Scott, James C. 1998. Seeing Like a State: How Certain Schemes to Improve the Human Condition Have Failed. New Haven: Yale University Press.

Shirky, Clay. 2008. Here Comes Everybody: The Power of Organizing Without Organizations. New York: The Penguin Press.

Silverstone, Roger and Leslie Haddon. 1996. Design and the Domestication of Information and Communication Technologies: Technical Change and Everyday Life. In Communication by Design: The Politics of Information and Communication Technologies, eds. Roger Silverstone and Robin Mansell, 44-74. Oxford: Oxford University Press.

Social Media Report Draft. 2009. University Withheld.

Sweney, Mark. 2010a. Tories make the most friends on Facebook. The Guardian, March 23. http://www.guardian.co.uk/media/2010/mar/23/conservatives-friends-facebook [Accessed 30/03/2010].

Sweney, Mark. 2010b. 'Advertisers should fear Twitter and Facebook more than regulators'. The Guardian, March 19. http://www.guardian.co.uk/media/2010/mar/19/advertising-twitter-facebook [Accessed 30/03/2010].

Trottier, Daniel and David Lyon. 2011. Key Features of a Social Media Surveillance. In The Internet and Surveillance, eds. Christian Fuchs, Kees Boersma, Anders Albrechtslund, and Marisol Sandoval, London: Routledge (forthcoming).

Turkle, Sherry. 2011. Alone Together: Why We Expect More from Technology and Less from Each Other. New York: Basic Books.

Wable, Akhil. 2009. Facebook Search Improved For Everyone. The Facebook Blog, August 10. http://blog.facebook.com/blog.php?post=115469877130 [Accessed 30/03/2010].

Ward, Katie. 2005. Internet Consumption in Ireland - Towards a 'Connected' Life. In Media, Technology and Everyday Life in Europe: From Information to Communication, ed. Roger Silverstone, 107-123. Aldershot: Ashgate.

Wittel, Andreas. 2001. Toward a Network Sociality. Theory, Culture \& Society 18(6): 51-76. 